\title{
Jóvenes y consumo cultural. Una aproximación a la significación de los aportes mediáticos en la preferencias juveniles*
}

\author{
Héctor Rolando Chaparro Hurtado** \\ Claudia Maritza Guzmán Ariza** \\ Recibido: 2016-09-02 Enviado a pares: 2016-09-23 \\ Aprobado por pares: 2016-11-06 Aceptado: 2016-12-11 \\ DOI: 10.22395 /angr.v15n30a6
}

\begin{abstract}
Resumen
El presente documento tiene como objetivo principal analizar críticamente las formas de significación y resignificación de la identidad en jóvenes pertenecientes al área urbana de la ciudad de Villavicencio (Colombia) frente a su consumo cultural, mediático y tecnológico. Es una acercamiento a la oferta cultural para el mundo juvenil que debe ser repensada seriamente, pues en voces de los propios jóvenes no existe una suficiencia en términos de actividades que satisfagan sus expectativas.

Palabras clave: Jóvenes, consumo cultural, identidad, culturas juveniles, sociedad red.
\end{abstract}

Trabajo asociado del proyecto de investigación "Jóvenes y consumo cultural: la reinvención de la identidad en la Sociedad red", financiado institucionalmente por la Universidad de los Llanos. Grupo de Investigación Juego, cuerpo y motricidad. COLOMBIA.

** Comunicador social y periodista. Especialista en Filosofía de la Ciencia. Máster en Sociedad de la Información y el Conocimiento. Doctorando en Estudios Sociales de América Latina. Profesor e investigador Universidad de los Llanos (Colombia).rchaparro@unillanos.edu.co

*.* Licenciada en Educación Física y Deportes. Magíster en Educación. Doctoranda en Estudios Sociales de América Latina. Profesora e investigadora Universidad de los Llanos (Colombia).cguzman@unillanos.edu.co 


\title{
Youth and cultural consumption an approximation to the significance of media contributions in youth preferences
}

\begin{abstract}
This paper's main objective is to critically analyze the forms of meaning and redefinitions of identity in young people from the urban area of the city of Villavicencio (Colombia) against their cultural, media and consumer technology, which involves diagnosing the preferences regarding with cultural, media and technology for young people located in this area in the city of Villavicencio, Colombia.
\end{abstract}

Key words: Young, cultural consumption, identity, youth cultures, network society.

\section{Juventude e consumo cultural: um estudo de caso, no departamento de Meta, na Colômbia}

\begin{abstract}
Resumo
O objectivo principal deste trabalho é analisar criticamente as formas de significado e redefinições de identidade em jovens da área urbana da cidade de Villavicencio (Colômbia) contra seus culturais, mídia e tecnologia de consumo, que envolve preferências diagnosticar a respeito com cultural, mídia e tecnologia para jovens localizadas nesta área na cidade de Villavicencio, o consumo Colômbia.

Palavras chaves: O consumo Jovem cultural, identidade, culturas juvenis, sociedade em rede.
\end{abstract}




\section{Introducción}

Este trabajo recupera principalmente la voces de los estudios sociales de la juventud, sobre todo de aquellos que insisten, como Rossana Reguillo (2003), en que buena parte de la literatura juvenil se ha sustentado en la perspectiva de su marginalidad o su actitud contestataria y rebelde; históricamente, el lenguaje, el vestido, ciertas prácticas rituales simbólicas, los formatos del consumo cultural y mediático y las preferencias deportivas, entre otras situaciones, no se pueden observar simplemente como mecanismos de distinción del mundo reglamentado y legislador del adulto, pues es indispensable verlas en todo su espesor.

De allí que buena parte de estas narrativas se haya centrado en una especie de discurso comprensivo, con sus interpelaciones hermenéuticas, fenomenológicas y constructivistas, que pone de relieve el carácter activo de los jóvenes y su potencial como sujetos estructuradores del mundo social. Esta afirmación excede las pretensiones esencialistas sobre la juventud y evita agotarse en la estadística o en la anécdota; en tal virtud, el Informe Juventud en España de 2008 se cuestiona, al margen de dichas orientaciones biologicistas, respecto de la situación de los jóvenes en el marco de políticas públicas que eventualmente no acogen sus expectativas, las transiciones a la vida adulta, la situación de la economía, el empleo y el consumo en la cambiante realidad de las sociedades globalizadas; el estado de la salud, las relaciones entre cultura, política y sociedad; la equidad de género, los fenómenos migratorios, en fin, alineaciones que responden más a procesos estructurales de comprensión del hecho de ser joven que a su mera descripción anatomofisiológica o su reducción como miembros inmaduros de un sistema, para el cual ellos significan una enorme sospecha. Para el caso colombiano, la apuesta académica es más bien reciente (1994, según Germán Muñoz), y está constituida básicamente por las relaciones políticas de los jóvenes en la ciudad de Bogotá.

En tal variedad de matices, Carles Feixa (2000) propone delimitar y clarificar el campo hacia el concepto de culturas juveniles, como "conjunto de vida y valores, expresados por colectivos generacionales en respuesta a sus condiciones de existencia social y material", lo que marca notablemente una diferencia en cuanto a la autonomía de los sujetos juveniles respecto de las instituciones adultas, y evita connotaciones de carácter peyorativo como "banda", "pandilla, "gallada", "barra" o, incluso, tribu, idea que se sustenta en la definición de reglas específicas de parte del grupo: mitologías particulares, uniformidad en el vestuario, actitud contestaría contra el mundo adulto, fuerte pertenencia al grupo y creación de marcas y señales propias.

Como se ve, el concepto "culturas juveniles" supera claramente varias de las inquietudes propuestas por los analistas sociales, en cuanto no se hace referencia únicamente a esa idea romántica y delirante, abiertamente heroica, de juventud, pero tampoco desde el discurso anatematizante, marginal y desviado. Por ello, Feixa propone hablar de culturas más que de cultura, debido al énfasis que se ha de entregar a su heterogeneidad y diversidad tanto "en el espacio como en la estructura social". De esa manera, también, las culturas juveniles se perciben como metáforas del cambio social, formas de subjetividad 
que reflejan el complejo de contradicciones de una sociedad en permanente renovación y cambio, que modifica continuamente sus valores (siempre en perspectiva de los valores hegemónicos), ya sean estas, formas de contrarrestar los valores emergentes de los procesos de globalización cultural (skin heads), el nacimiento de un mercado adolescente (hoppers) o el nihilismo neorromántico (emos).

Sumariamente, la idea de culturas juveniles engloba tanto las formas contrahegemónicas (contracultura) de ser joven como las perfectamente incluidas, evitando odiosas homogeneizaciones para todas sus formas y estilos, atravesados por elementos culturales como la música, el lenguaje, la estética, las producciones culturales y las actividades focales. Como se ve, todo un entramado que requiere cuidadosa revisión por parte de las ciencias sociales y los estudios sociales de la educación, que propone una mayor rigurosidad y juicio para evitar sesgos y simplificaciones.

En este sentido, Muñoz (2007) reconoce en uno de sus trabajos la ausencia de los asuntos juveniles en las agendas públicas colombianas, ante lo cual "El gran desafío es tomar conciencia del protagonismo de los jóvenes y potenciar la visión de y sobre los jóvenes como "sujetos de derechos", para el ejercicio pleno de la ciudadanía y el establecimiento de garantías sociales e institucionales, el respeto y cumplimiento de sus derechos fundamentales. (p. 14) Derechos que incluyen - para el autor-, la cultura y sus expresiones, abandonada a las lógicas adultocéntricas que limitan la visión de lo juvenil al cuidado o la sospecha; la educación, como escenario fundamental para el acceso al mundo del trabajo, pero también como espacio para la socialización y la construcción de la subjetividad propia; el empleo, precario, mal pagado y atravesado por requerimientos de experiencia; la salud, por ejemplo en la educación sexual más allá de enfoques moralistas, o la comunicación, en el terreno expresivo y en la visibilidad de sus intereses. Temas y problemas que tienen enormes semejanzas en los países que constituyen la "patria grande" latinoamericana.

Tránsito, pues, de objetos a sujetos, de actores a agentes, de cifras a realidades inconfesables, los jóvenes han permitido en la variada realidad latinoamericana un complejo de situaciones teóricas y metodológicas que se tratan de explicar e interpretar a la luz de una realidad social que, como se señaló en un principio, puede ser curiosamente similar en nuestros países, y que por ello debe ser vista en clave regional teniendo cuidado de reconocer su carácter heterogéneo, diferencial, diverso. O, en palabras de Germán Muñoz,

[...] pienso que es coherente proponer una línea de pensamiento donde los/ las jóvenes sean vistos como 'agentes culturalmente activos', es decir, personas que asumen su auto-creación y la construcción de 'prácticas de libertad' y 'formas aceptables de existencia' en el entorno humano más cercano, el de ciudadanías juveniles (Muñoz, 2007, p. 38).

\subsection{Juventud y culturas juveniles}

En una perspectiva antropológica, la juventud es una construcción social y cultural relativa en el tiempo y en el espacio. Feixa (1993) demuestra cómo cada sociedad organiza ese momento del ciclo vital ubicado entre la infancia y la vida adulta, modelando específicamente 
las formas y contenidos de esta transición. Así, las formas de juventud son cambiantes según sea su duración y su consideración social, y sus contenidos dependerán de los valores asociados a este grupo de edad y de los ritos que marcan sus límites.

En Europa occidental, la juventud como categoría social surge hacia fines del siglo XVIII. Algunos autores observan que la juventud existe desde el siglo XVI, pero su conceptualización tiene que esperar al siglo XVIII. La idea de juventud corresponde a la conciencia de la naturaleza particular de aquellos caracteres que distinguen al joven del niño y del adulto; la sociedad asume y reconoce a la juventud como una fase específica de la vida durante la cual -a través de un conjunto de prácticas institucionalizadas- le son impuestas al individuo ciertas demandas y tareas que definen y canalizan sus comportamientos como "joven", las cuales suponen una relación con la "idea de juventud" (Feixa, 1993b).

El siglo XX, y sobre todo la segunda mitad del mismo, irán construyendo y definiendo lo que hoy entendemos como juventud. Avelló y Muñoz (2002) observan que en la actualidad "una de las vías más fructíferas a la hora de tipificar al 'joven' es hacerlo a partir de lo asistido o desasistido que se encuentra por parte del sistema social y, lo que se deriva de ello, del proceso de dependencia que se genera en dicha relación".

Lo anterior quiere decir que la percepción y la conceptualización de la juventud moderna fueron construidas en función "de la superación de un repertorio de dependencias concreto" (Avelló y Muñoz, 2002). La "libertad" adulta a la que debería acceder (trabajo, lugar propio, familia distinta a la de origen, autonomía para tomar decisiones), según el modelo adultocéntrico de la Modernidad, se hace hoy en día cada más difícil de satisfacer por parte de las instituciones sociales. Este es el origen de la prolongación contemporánea del estatus "juvenil", en el sentido dependiente, entre la mayoría de la población en cada país.

En otra orilla, Bourdieu observa que la juventud y la vejez no están dadas, que son construcciones sociales y culturales relativas en el tiempo y en el espacio y sus fronteras son objeto de lucha. Es decir, la organización social de los momentos del ciclo vital que modelan específicamente las formas, los contenidos y los tiempos de la transición, entre una etapa y otra, están atravesados por la cuestión del poder, por "la división (en el sentido de repartición) de los poderes". Cualquier clasificación por edad es "siempre una forma de imponer límites, de producir un orden en el cual cada quien debe mantenerse, donde cada quien debe ocupar su lugar" (Feixa, 1993b, 1998b; Bourdieu 1990). Y ese "orden", en el caso de la juventud, es su condición de dependencia y subordinación ante los adultos.

Es necesario partir de que la juventud no existe realmente; existen sociedades de jóvenes histórica y culturalmente constituidos en la heterogeneidad: de clases sociales, de personas, de cuerpos y lenguajes totalmente distintos que tienen sus espacios y tiempos a su manera, individuos, seres exclusivos, con sus formas particulares de vivir solos, juntos, o no solos ni juntos. Esta es una compleja situación de comprensión frente a lo que realmente ha sido y ha revelado la juventud a través de la historia. Siempre se ha estipulado que los jóvenes son una unidad social y un grupo legalmente constituido que 
posee intereses comunes. Por tanto, juventud es no ser sujeto. Sin embargo, el adulto empieza a ponerse en condiciones de disputar la verdad mediante el saber, lo cual lo hace autoritario, tratando nuevamente de superarse a sí mismo, situación que requiere liberarse nuevamente del tutor en que él mismo se ha convertido o ser abolido por el otro, poniendo en claro el movimiento de relevo generacional, pues se convierte en un proceso de regresión y progreso, donde la juventud se asume como amenaza, revolución o reforma que debe generar un cambio social hacia la representación del futuro.

Para mitad del siglo XX se instaura una afirmación muy propia para hablar de juventud: en este contexto, los jóvenes se volvieron visibles como problema social.

Eric Hobsbawm (2013), por ejemplo, determinó que la cultura juvenil genera una revolución cultural. En esta época confluyen cambios en la complejidad inestable de sus manifestaciones. Los nuevos movimientos culturales expresan y amortiguan este conflicto generacional que se despliega por ondas que pueden ser atravesadas por la continuidad del movimiento cultural. Un elemento de análisis alternativo, el de las culturas juveniles, describe las maneras en que las experiencias sociales de los jóvenes son expresadas colectivamente mediante la construcción de estilos de vida distintos, localizados fundamentalmente en el tiempo libre o espacios de intersección de la vida institucional. Se refieren a la aparición de "microsociedades juveniles" con grados significativos de autonomía respecto de las instituciones adultas, que se dotan de espacios y tiempos específicos y que se configuran históricamente en los países occidentales, principalmente en Europa, Estados Unidos y Canadá, tras la Segunda Guerra Mundial, lo cual coincide con grandes procesos de cambio social en el terreno económico, educativo, laboral e ideológico (Feixa, 1995).

De esta manera las culturas juveniles se entienden como prácticas de libertad, capacidad para inventarse la vida (Marín y Muñoz, 2002), formas de manifestarse con nuevas subjetividades en un mundo en el que se ha priorizado la imposibilidad de ser, y de ser con otros. Son una construcción sociocultural con historias propias que rompen con la idea universal de "juventud", y son relevantes las contingencias particulares de cada una de estas culturas, sus formas de expresión y su diversidad, lo que implica reconocer las mutaciones que sufren estas formas de subjetivación, sus tránsitos y recorridos, así como la generación de nuevas formas de ser, puesto que están mutando y renovándose permanentemente. La dimensión cultural busca visibilizar a los jóvenes como productores de sentidos y sinsentidos, lo cual entraña

[...] un cambio en las miradas tradicionales de pensar lo juvenil, trascender lo sectorial, pensar lo transdisciplinar. Implica también una forma de rechazo a la nueva cartografía de las visibilidades que pretende visibilizar las relaciones sociales y simbólicas, y la producción cultural para luego ser utilizada y domesticada en la mercantilización de la vida cotidiana y la industrialización de los bienes simbólicos (Hurtado, 2007, p. 13).

Es en la Modernidad-mundo donde empiezan a forjarse las culturas juveniles, lo que obliga a entender que existen representaciones, prácticas sociales, constitución de 
identidades y "culturas juveniles" como metáforas de cambio social (Reguillo, 2000, p. 64). Los jóvenes son rebeldes, revoltosos, subversivos, guerrilleros, delincuentes, sicarios, drogadictos, violentos y terroristas. Estas clasificaciones se empezaron a expandir rápidamente y se visibilizaron ante el espacio público, asumiendo que conquistaron su mayoría de edad. El concepto juventud, por consiguiente, debe comprenderse desde su perspectiva cultural, que puede existir o no existir: algunos prefieren hablar de juventudes, culturas, identidades o mundos juveniles. En Colombia, la juventud se convertiría en un fenómeno generado por las interrelaciones que se dan entre la familia, la educación y el trabajo previo y de preparación para el ejercicio de roles ocupacionales y familiares adultos. Pero al mismo tiempo, surgen otras formas diferentes de juventud que hacen más complejo el análisis.

Se abre otro elemento que es importante analizar y son las prácticas juveniles; la sociedad contemporánea ha construido la categoría joven, el cual se constituye en sujeto social, cambiante y discontinuo, cuyas características son asociadas y resultan de una negociación-tensión entre la categoría sociocultural determinada por la sociedad particular y la actualización subjetiva que los sujetos llevan a cabo a partir de los esquemas de las cultura vigentes.

Como resultado de muchos procesos y cuestionamientos se define que ya no es la juventud la que se enuncia sino los jóvenes, las juventudes, lo juvenil, las contraculturas, subculturas, transculturas, culturas juveniles, inidentidades, identidades, búsquedas epistémicas sobre el sujeto, el objeto y el método. Inclusive, se establece que los jóvenes están elaborando "culturas prefigurativas", aquellas en los cuales los adultos aprenden de los niños. Es una manera de asumir una nueva autoridad mediante esas figuras de un futuro aún desconocido. Y al ser convertidos los jóvenes en objetos de estudio por los científicos sociales, empiezan a ser percibidos con mayor respeto: se buscan posibilidades de encontrar en ellos otras perspectivas interpretativas y hermenéuticas, y también otra subjetividad que se reconozca en ellos. Los jóvenes, pues, se convertirán en sujetos pensados y en sujetos de discursos, con posibilidad de movilizar objetos sociales y simbólicos, es decir, de ser agentes sociales (Reguillo, 2000, p. 36).

Pensar los jóvenes hoy en la cultura es una tarea fundamental: Martín Barbero (1998) afirma que

[...] pensar los procesos culturales se ha vuelto una tarea de envergadura, ya que lo que está en juego son hondas transformaciones en la cultura cotidiana y especialmente en la de los jóvenes, que se están apropiando de la modernidad sin dejar su cultura oral.

En esta perspectiva, los jóvenes que se han convertido en protagonistas importantes no solo en este momento histórico sino desde la década de los sesenta cuando se conformaron los múltiples movimientos estudiantiles que contribuyeron y cimentaron las bases de nuevas formas de participación social y cultural con las cuales manifestaban su rechazo a las formas políticas, sociales y culturales constituidas como dominantes. 
El siglo XXI se inicia con un panorama desconcertante y desolador, ya que el proyecto globalizador y neoliberal hacia el cual se enrutan muestras sociedades tiene como epicentro las profundas crisis desde el orden político-social: los jóvenes, de diferentes maneras y en inferioridad de condiciones, han venido señalando, pero, además, desconfigurando las grandes certezas que dicho proyecto globalizador plantea, señalando a través de diferentes manifestaciones y escenarios en los cuales se hacen presentes que el proyecto social que se privilegió para nuestra región hasta ahora está siendo incapaz de plantear alternativas o posibilidades de un futuro incluyente, justo, igualitario, esperanzador, pero sobre todo posible.

En este sentido la pregunta por los jóvenes en este mundo globalizado cobra especial interés, ya que es necesario pensar la manera como ellos están haciendo interpretación del mundo, la manera como lo entienden, la manera como lo justifican, la manera como lo intervienen, la manera como lo viven, un mundo atravesado por un sinnúmero de conflictos, de tensiones de matices, de órdenes, desordenes, de pluralidades, de intereses, de reconfiguraciones económicas, políticas, sociales y culturales, que camina directo a las paradojas del neoliberalismo globalizado desde el cual parece cimentar firmemente sus raíces en los valores de la localidad es apremiante.

\subsection{Postmodernidad, TIC y sociedad red}

En La condición postmoderna. Informe sobre el saber, el filósofo francés Jean-François Lyotard efectúa una crítica a la Modernidad desde sus múltiples perspectivas: como proyecto de la Ilustración y su apuesta por sus ideales libertarios y de justicia social. En ello contrasta, notablemente, con la apuesta teórica del pensador alemán Habermas (1982), para quien ciertamente la Modernidad es un proyecto inacabado que requiere de concreción, y a diferencia de él, Lyotard, considerado el "padre de la Postmodernidad", propone su partida de defunción fundamentalmente por no haber cumplido con sus promesas y compromisos legados por la Revolución Francesa: libertad, igualdad, solidaridad.

En este sentido, su informe elabora una seria reflexión en torno del estatuto del saber en las sociedades de la época (1987), sociedades informatizadas, caracterizadas por encontrarse en etapa de transición del industrialismo y que las ha llevado a ser consideradas posindustriales. Este estatuto del saber, ciertamente, se modifica en la medida en que cambian las sociedades, legitimado por el lenguaje, interpelado por los discursos que se construyen a su alrededor, por los medios que lo informan y las construcciones teóricas de la comunicación, entre otros fenómenos.

Desde esta perspectiva, el saber se ve afectado en sus dos funciones principales: la investigación y las formas de divulgación. De allí se desprende la importancia que las tecnologías de la información y la comunicación (TIC) poseen en este marco referencial, en la medida en que estas "máquinas de información" generan profundas transformaciones en las formas en que la información se genera, se procesa y se almacena. Por ello, para Lyotard el saber en las sociedades postmodernas está reconocido como una nueva producción, quizá la principal fuerza de producción, que repercute en nuevas formas de 
afectación de sociedades en vías de desarrollo y produce fracturas inocultables en los países que se encuentran a un lado u otro del paisaje del desarrollo económico.

Adicionalmente, hay que decir que las TIC modifican las formas de acceso a la información, y por tanto la construcción del conocimiento, el trabajo de carácter cooperativo / asíncrono, las rutinas escolares, los vínculos societales y las formas de subjetividad humana, entre otras situaciones. Por esta vía, Lyotard asigna el problema de la legitimidad de este saber reconfigurado al "legislador", en este sentido a las comunidades científicas, en permanente conflicto, con lo que se confirma la existencia de una intrínseca relación entre saber y poder.

De esta manera, las TIC constituyen el elemento posibilitador para que la producción, el procesamiento, la organización, la comunicación, transmisión y gestión se conviertan en la base del funcionamiento de la sociedad actual, con lo que emerge la idea de la existencia de una economía informacional que distancia, notablemente, la sociedad informacional de la sociedad global, es decir, entornos que significan una nueva trama social que depende en mucho de la digitalización, la informatización, la telemática y la memorización para su concreción como forma social.

Esta estructura social afecta sensiblemente diferentes esferas de la cotidianidad humana como la economía, la guerra, la investigación científica, la prensa, el ocio y la cultura, pero simultáneamente genera significativas fronteras sociales: los "inforricos" y los "infopobres", o lo que es lo mismo, la evidencia concreta del digital divide y de sus inocultables consecuencias en las formas en que los sujetos acceden a la información en contextos determinados. Ello concuerda con las lógicas de inclusión y exclusión con las que trabajan las estructuras sociales de la sociedad red en la propuesta del investigador español Manuel Castells, que consiste en una estructura social construida por redes de información que tiene como objetivo el procesamiento, almacenamiento y transmisión de información sin que exista restricción de alguna naturaleza en términos de distancia, tiempo o volumen. Ello no implica, como se ha pensado, cierta forma de homogeneización de los formatos, estilos y gramáticas culturales, pues, como plantea el autor catalán,

[...] lo que caracteriza a la sociedad red global es la contraposición de la lógica de la red global y la afirmación de la multiplicidad de identidades locales (pues) más que la aparición de una cultura homogénea global, lo que puede observarse como tendencia más común es la diversidad histórica y cultural: fragmentación más que convergencia (Castells, 2004, p. 69).

Así que Castells le apuesta al reconocimiento de la importancia de lo local en las experiencias humanas, en perspectiva territorial tanto como cultural, aunque de la misma forma propone la idea de que se potencien el trabajo cooperativo y colaborativo, la "interacción constante y flexible" (Castells, 2006, p. 53) de las relaciones de dominación entre redes y los efectos - ¿̇acaso previsibles?- de la irrupción de estos nuevos formatos sociales en la mayoría de las actividades sociales humanas: en la economía (la empresa red) y las formas de adscripción al grupo, en las relaciones interpersonales, en el sistema educativo y la producción cultural o en las formas de interpelación ciudadana. 


\subsection{Consumo e industria cultural}

Otro elemento que caracterizó este período de posguerra está relacionado con la manera como nace la creciente y próspera industria cultural, que de manera particular ofrece la gran posibilidad de bienes y servicios exclusivamente para el consumo de los jóvenes. En este sentido nos aproximamos a la noción de consumo como "el conjunto de procesos de apropiación y uso de productos en los que el valor simbólico prevalece sobre los valores de uso y cambio, o donde al menos estos últimos se configuran subordinados a la función simbólica" (García Canclini, 1999, p. 42).

De esta manera, los jóvenes de los países desarrollados o de altos ingresos acceden a unas nuevas posibilidades de bienes y servicios, entre otras cosas, por la capacidad de su poder adquisitivo, lo que, además, hizo que hubiera un reconocimiento generalizado de las nuevas maneras como se visualizaban los jóvenes y dio indicios de nuevas identidades que rápidamente se extendieron por muchas regiones del mundo. Esto generó un nuevo modelo para los jóvenes, el cual debía ser aceptado, acogido y difundido generando una revolución no solo desde lo cultural sino también desde lo económico. Para el historiador Eric Hobsbawm (1995), la cultura juvenil se convirtió en la matriz de la revolución cultural del siglo XX, visible en los comportamientos y costumbres, pero sobre todo en el modo de disponer del ocio, que pasó a configurar cada vez más el ambiente que respiraban los hombres y mujeres urbanos (p. 331).

Este tipo de estudios ha ido cobrando fuerza en el terreno de las prácticas sociales juveniles, ya que las nuevas formas en que los jóvenes se agrupan van reconfigurando las nociones a partir de las cuales manifiestan intereses o desprecios por los fenómenos sociales. El consumo cultural de radio, televisión, internet, etc., en términos operativos, generalmente se entiende como acceso a bienes y servicios tales como libros, discos y fonogramas, funciones de cine, conciertos, representaciones teatrales y danza, diarios, revistas o televisión. Estos estudios se convierten en herramientas de vital importancia para rastrear y visualizar los usos, las codificaciones, las descodificaciones y las recodificaciones de los significados sociales que tienen para los jóvenes las nuevas formas de distribución y de geopolíticas en nuestra sociedad. Esta relación que se establece con los bienes culturales como espacios o lugares de tensión, pero, a la vez, de negociación de los significados culturales, el consumo cultural como forma de identificación-diferenciación social (Bourdieu, 1988; García Canclini, 1991) ponen en el centro de la discusión la importancia que genera en las nuevas dinámicas sociales la consolidación de una cultura-mundo que afecta, de manera significativa, las formas de vida, los patrones socioculturales, los aprendizajes y particularmente las formas de interacciones sociales contemporáneas.

Si el consumo sirve para pensar, como ha señalado García Canclini, es porque su análisis permite entender las distintas configuraciones del mundo que de maneras contradictorias y complejas los jóvenes construyen a partir de sus vínculos con las industrias culturales pero anclados en sus propios colectivos o lugares de significación (Reguillo Cruz, 2000, p.71). 
Estas razones son, tal vez, la pista más importante para entrever que ya estamos en el umbral de cambios profundos, pero no vemos muy bien qué es lo que viene detrás, y una manera para comprender lo que se avecina tiene que ver con la superación de aquellas "dicotomías" que vivimos los adultos entre juego-trabajo, consumo-producción, seriofestivo, juego-aprendizaje, estético-argumental cognitivo; si no tenemos en cuenta esto, no vamos a poder entender que el modo como se relacionan los jóvenes con las nuevas tecnología, especialmente con la Internet, no es con el aparato, sino con una mediación, a través de la cual navegan, para denominar la manera de leer, escribir, nombrar e inventar en la Internet.

La manera como los jóvenes viven hoy esta especie de comprensión cultural no tiene que ver únicamente con los modos de entrelazamiento de las diferentes prácticas, ya que los jóvenes siguen yendo a las salas de cine, accediendo más a Internet, y en general a los diferentes espacios culturales ofrecidos. De esta forma, se revela una nueva manera de circular los productos culturales frente a un actor que no separa radicalmente el consumo de la producción, el ocio del trabajo, no solo porque ya podemos trabajar en casa, sino porque dentro del ocio puede haber una dimensión del trabajo, una dimensión de producción, una dimensión de creatividad que transforma enormemente la relación puntual de la gente con las diversas modalidades de la cultura en una relación mucho más duradera a su modo, y mucho más creativa.

En este ejercicio, el proyecto se concentró en analizar críticamente formas de significación y resignificación de la subjetividad en jóvenes pertenecientes al área urbana de las ciudades de Villavicencio, Acacías, Granada, Puerto López y Lejanías frente a su consumo cultural, mediático y tecnológico. Entre los objetivos específicos, la ejecución del proyecto de investigación decantó las siguientes:

- Diagnosticar las preferencias en relación con el consumo cultural, mediático y tecnológico de los jóvenes pertenecientes al área urbana de las ciudades de Villavicencio, Acacías, Granada, Puerto López y Lejanías el departamento del Meta.

- Establecer formas de interpretación de la realidad juvenil en cinco municipios del departamento del Meta.

- Definir criterios de acercamiento con la juventud, en tanto actor fundamental en la definición de políticas públicas en materia cultural.

- Generar procesos de comprensión y análisis sobre las formas de interacción juvenil y sus formatos de socialización en la construcción de sus subjetividades.

\section{Materiales y métodos}

El proyecto se desarrolló de forma cuali-cuantitativa en un estudio de tipo descriptivo, que incluyó la elaboración de una encuesta de 44 preguntas, validada por pilotaje efectuado en el municipio de Villavicencio y aplicada a 3004 jóvenes (14 a 27 años, según la legislación colombiana) en los municipios de Acacías y Restrepo (Región Piedemonte) 
Granada y Lejanías (Región Ariari) y Puerto López (Región Río Meta). El instrumento fue revisado y aprobado por tres expertos.

Adicionalmente, y para satisfacer necesidades del orden cualitativo relacionadas con las expectativas, deseos y opiniones de líderes de opinión en el ámbito cultural, se llevaron a cabo 16 entrevistas semiestructuradas con igual número de sujetos, en las que se indagaba, de manera especial como criterios de análisis, acerca de la toma de decisiones en el campo cultural, políticas culturales y su incidencia en espacios creativos, oferta cultural, intereses y conceptualización y significación de cultura. Los criterios de análisis definidos para el estudio están relacionados con consumos de medios impresos, audiovisuales y digitales, además de la relación de la cultura con los mundos juveniles, sus formas de acceso y su importancia para la definición / construcción de su subjetividad.

Como se anotó con antelación, se tomó una muestra de 3004 jóvenes habitantes de algunos municipios del departamento del Meta (de los que se excluyó a la ciudad capital, Villavicencio), seleccionada empleando la técnica de muestreo aleatorio según la fórmula $\mathrm{n}=\left(Z^{\wedge} 2 N P Q\right) /\left(E^{\wedge} 2(N-1)+Z^{\wedge} 2 P Q\right)$. La encuesta incluyó aspectos generales relacionados con edad, estrato socioeconómico y grado de escolaridad.

La información acopiada se organizó y analizó siguiendo el curso de los objetivos propuestos para la investigación. Para el caso de la encuesta, la cual pretendía definir las preferencias de los jóvenes en cuanto a su consumo en materia de bienes y servicios culturales, se sistematizó la información y se hizo un compendio general de dicho instrumento entre los sujetos de análisis.

Las entrevistas semiestructuradas realizadas permitieron establecer el análisis conversacional desde la perspectiva pragmática del lenguaje, y los resultados obtenidos en el estudio son mostrados conforme fueron señalados en los objetivos específicos. Estos aparecerán de forma consecutiva para dar estructura al documento y los documentos asociados como producción.

\section{Resultados}

El mayor índice de participación de jóvenes se encuentra entre las edades de 15 (894 sujetos), 16 (572) y 17 años (604). Por el contrario, los menores rangos de participación en las encuestas se presentan en edades de 26 (3), 25 (5) y 27 años (7). Aunque la muestra significativamente genera un rango de participación en edades de 14 a 27 años, de diferentes estratos socioeconómicos y de diferentes niveles educativos del sistema escolar, ofrece un espectro importante de participación y muestreo que garantiza la confiabilidad de los datos y la importancia del estudio.

En este sentido, la mayor concentración de los encuestados se ubica en los estratos 1 y 2 (1 264 y 1 442, respectivamente), con menor presencia comprendida entre los estratos 5 (3) y 6 (1).

La mayor concentración de los encuestados se encuentra en los niveles de escolarización Secundaria (2 547). Es importante destacar aquí la pregunta por los diferentes focos 
de atención: por un lado, estudiar lo que ocurre en la Secundaria y en la universidad, y por otra parte, definir la experiencia propia de los jóvenes que estudian en las instituciones, ya que como lo afirma Benedicto (2002: 29) "solo teniendo en cuenta la multiplicidad de prácticas culturales podemos comprender cómo los diferentes actores definen sus preferencias y dotan de significado los procesos políticos en los que están inmersos".

En relación con los propósitos de la encuesta, los sujetos de estudio manifiestan un reconocimiento importante a la cultura, entre quienes le otorgan mucha importancia (2 828 personas, 94 \%), y (206, 6 \%) de los jóvenes que no le asignan importancia alguna.

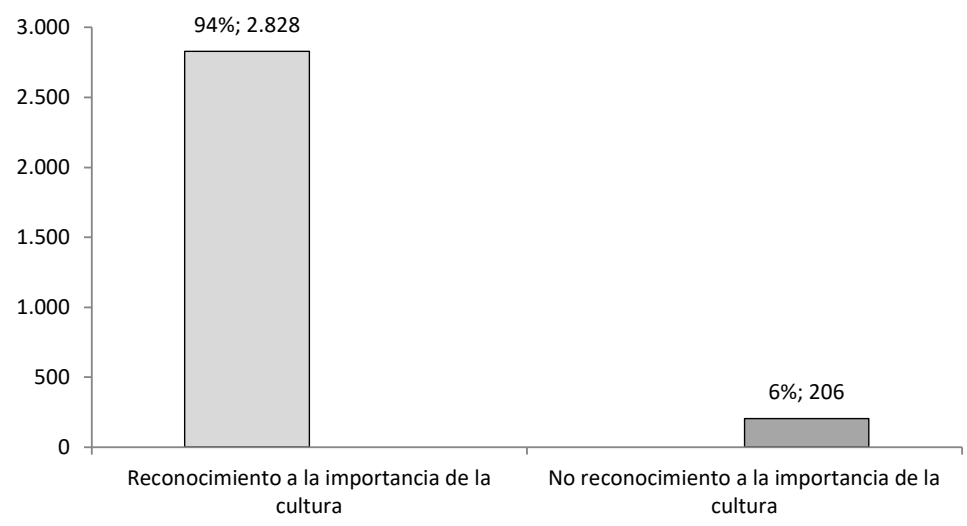

Gráfica 1. Reconocimiento a la importancia de la cultura

Fuente: elaboración propia

Situación que demuestra cómo los jóvenes manifiestan interés por los espacios de apropiación de los procesos culturales, y cómo de diferentes maneras los jóvenes articulan, en un gran porcentaje, a sus actividades cotidianas los procesos de apropiación de la cultura. Es necesario señalar que los jóvenes, a través de estos espacios de apropiación van abriendo espacio de apoyo, sociabilidad y reconocimiento, lo que permite amplias posibilidades de desarrollo de potencialidades de la subjetividad en los jóvenes.

De esta misma forma, se hace necesario enfatizar en el hecho de que, para algunos, el ámbito de lo cultural genera espacios de sensibilización humana relacionadas más con el desarrollo de sus potencialidades, de manera que la encuentran

[...] muy relacionada con diversas expresiones que puede tener el ser humano entonces como desde el arte, la cultura o el hecho de generar una conversación interesante. Son elementos que de una u otra forma le dan sentido a la vida de uno, entonces desde mi punto personal es el hecho de qué me genera como un sentido frente a las cosas (Johana, 23 años).

O aquellos que lo encuentra definitivo para los procesos de socialización:

[...] para mí lo cultural es muy importante como para mi vida y como para la vida de los demás, es como algo que nos identifica a cada uno, entonces eso 
es como algo importante de cada uno, y así uno lo puede dar a conocer a las demás personas (Daniela, 15 años. Granada).

De la muestra seleccionada, 2292 jóvenes manifiestan no estar de acuerdo con el presupuesto asignado a actividades relacionadas con la cultura, es decir, el $76.2 \%$, un porcentaje significativo si tenemos en cuenta el 73,6 \% que está de acuerdo con los eventos que organizan los agentes culturales, vale decir, institutos de cultura en los niveles seccional (departamental) y local (municipal).

Contexto en el cual los jóvenes del departamento del Meta manifiestan participar como creadores y artistas en un porcentaje mayoritario de $60,8 \%$ de la muestra seleccionada, entre quienes han optado por hacerlo en actividades artísticas relacionadas con la danza folclórica (814, $27 \%$ ), literatura (376, 12,5 \%) y música (352, 11,7\%).

Esta lectura permite reconocer en términos políticos las expresiones culturales de los jóvenes, lo cual arroja información sustantiva sobre el modo en que están entendiendo el espacio público. De igual manera, posibilita entender los espacios de expresión juvenil, dotar a la ciudadanía de las herramientas fundamentales para su constitución y empoderamiento, así como atender la lógica de la vida cotidiana, lo que permite entender por dónde pasan, desde la perspectiva de los propios jóvenes, sus críticas y demandas al sistema.

Selección en la que el contexto familiar juega un papel definitivo, si tenemos en cuenta el papel que padres y maestros juegan en el desarrollo de estas apuestas por la configuración de su subjetividad en edades tempranas:

[...] los inicios se dan desde los 4 años de edad cuando mi mamá quiso impulsar. A ella le gusta mucho la danza y quiso meterme aquí en el cuento de danzas. No me gustaba mucho, era algo que ella realmente... pero la insistencia de ella fue tal que pues le cogí tanto amor a esto que llevamos toda la vida desde que tengo uso de razón haciendo lo que me gusta que es bailar joropo. Eso se da aquí como formadora. Así la mayoría de bailadores (Hernán, 26 años. Acacias).

Y, sin embargo, en lo relacionado con asistencia a actividades culturales (museos y exposiciones), los resultados plantean muy claramente la poca frecuencia (1 456, 48,5 \%) con que los jóvenes participan de estas actividades, frente a 39,6 \% que nunca lo han hecho por razones fundamentalmente asociadas a la escasa oferta (47,3\%), la falta de divulgación (15,9\%) o el desinterés (12,3\%).

De lo anterior se infieren claramente deficiencias que los jóvenes encuentran en la oferta cultural en estos ámbitos de museos y espacios públicos para la exposición artística. Es claro que para dar significado a cualquier experiencia, se requiere la capacidad de ser conectada con lo que ya se conoce. Las exposiciones tienen la capacidad de estimular las comparaciones entre lo nuevo y lo desconocido, y por lo tanto, establecen conexiones y acceso a conceptos y herramientas conocidas para establecer tales comparaciones. En este sentido podemos contemplar los museos como artefactos culturales e ideológicos que pueden ser analizados como sistemas de significación o como sistemas de comunicación que utilizan signos y señales comprendidas y leídas socialmente que subrayan el hecho 
de que las personas construyen y definen significados de las experiencias vividas, en las que cada elemento toma lugar en los sistemas individuales de significación.

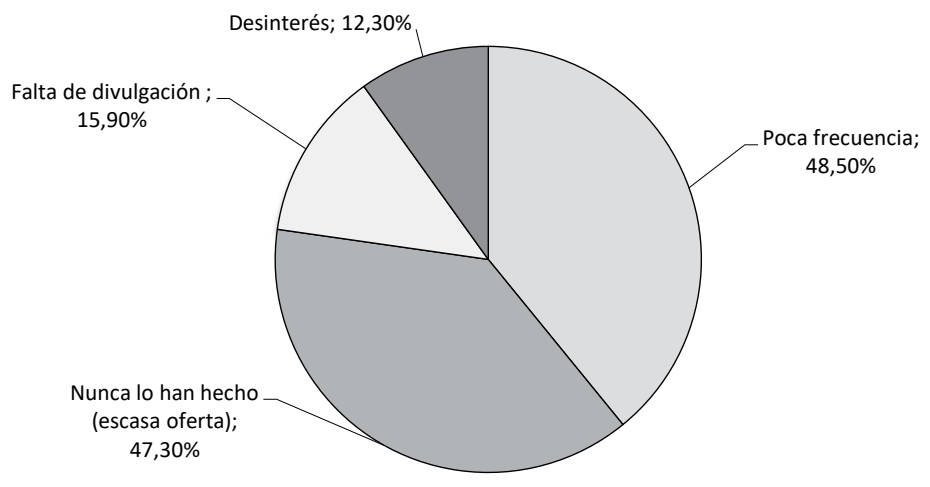

Gráfica 2. Asistencia a eventos culturales.

Fuente: Elaboración propia

Igual situación acontece con la asistencia a espectáculos teatrales o cine, en el que el porcentaje mayoritario de los encuestados afirmó no asistir a actividades de esta naturaleza (47,3\%) o hacerlo con poca frecuencia (42,2 \%). Esto es realmente significativo, ya que en sumatoria el $89.5 \%$ de los encuestados manifiesta que con muy poca frecuencia o nunca asiste a cine o al teatro. Como en anteriores preguntas, esta inquietud se relaciona claramente con la escasa o nula difusión de las presentaciones artísticas en el área de teatro y el poco interés que se tiene en la región por desarrollar propuestas que acerquen a los jóvenes sus prácticas culturales preferidas.

Algunos datos asociados a las formas de consumo cultural en los jóvenes del departamento del Meta sujetos de análisis arrojan, como generalidad, preferir géneros cinematográficos de terror ( $1051,34,9 \%$ ) o tener una frecuencia de lectura de libros de una vez a la semana (1 071, 35,6\%; manifestó no haber leído libros nunca), y leer preferentemente novelas (43,7 \%) por encima de cuentos (36,6 \%), poesía ( $15,2 \%$ ) o libros de autoayuda $(9,1$ $\%$ ). El interés de los jóvenes en la lectura está relacionado con un pasatiempo, seguido por expectativas educativas (766, 25,4 \%) o informativas (777, 25,8\%).

Ante la inquietud planteada en el cuestionario acerca de sus relación con la música, un mayoritario 99,8 \% (2 999 encuestados) manifiesta su gusto por la música, y en géneros como el vallenato (976, 32,4\%), reggaetón (872, $29 \%$ ), balada (584, 19,4 \%), pop (581, 19,3 \%) y cross over (302, $10 \%$ ). Es significativo el hecho de que la música folclórica (joropo) ocupa un $12,4 \%$ de las preferencias musicales de los jóvenes, aunque la oferta cultural del departamento está concentrada casi específicamente en la difusión de las músicas folclóricas. 


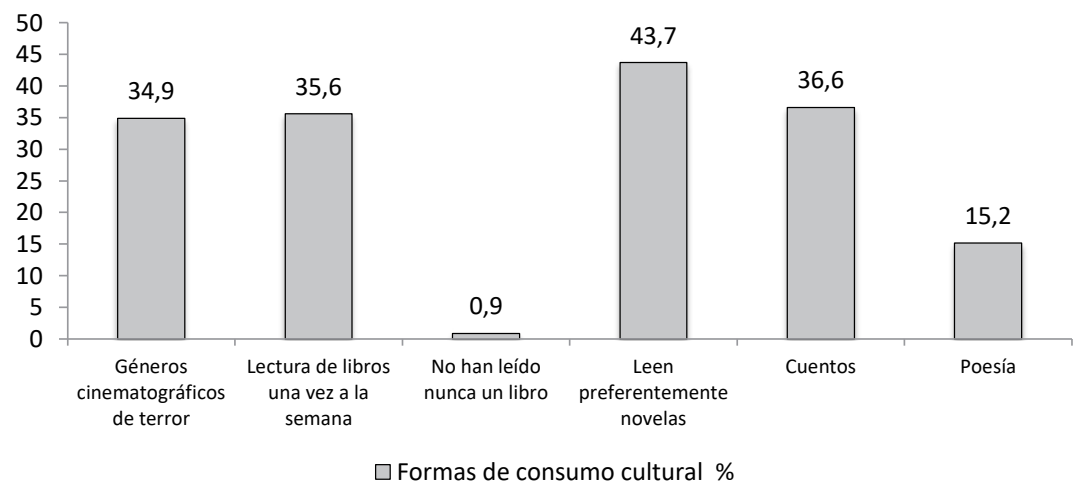

Gráfica 3. Formas de consumo cultural.

Fuente: elaboración propia

\subsection{Consumo digital}

De los encuestados, el 77,3 \% tienen computador en sus hogares. Es importante el hecho de que, aunque se han efectuado grandes esfuerzos por masificar su uso, el computador personal (PC) no ha generalizado su utilización. Si a eso le añadimos que los encuestados pertenecen preferentemente al estrato 3 , estaremos hablando de una nueva forma de brecha digital (digital divide) que deriva en formas de incomprensión de los lenguajes informáticos, ocasionando eventualmente fenómenos de exclusión, analfabetismo funcional y otros inconvenientes que fácilmente pueden revertirse en problemas de carácter social.

El porcentaje de jóvenes que tiene acceso a internet (51,6\%) desde sus hogares informa sobre la popularización del uso y apropiación de esta tecnología de parte de los jóvenes del departamento del Meta en los sectores urbano y rural, así como de un importante 49,2 \% de quienes no tienen acceso a esta tecnología de la información y la comunicación TIC.

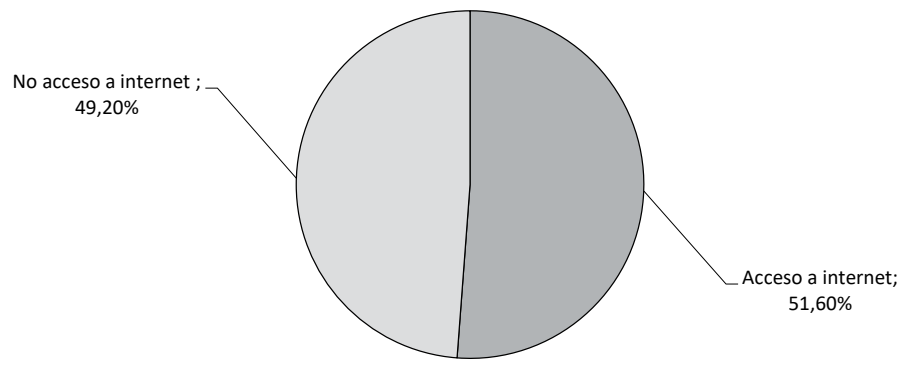

Gráfica 4. Jóvenes conectados

Fuente: elaboración propia 
Desde esta mirada, y según su criterio, aquellos que tienen acceso tienen mejores oportunidades para sus desarrollos personales están permanentemente conectados con sus amigos y acceden más fácilmente a tareas y trabajos. Los jóvenes en general identifican Internet como una tecnología de relación, de interacción que guarda una continuidad con su amplia cultura audiovisual. Si bien gran parte de los encuestados no tiene esta tecnología, se trata de un medio muy presente en el imaginario de los jóvenes y de sus familias: se sienten satisfechos de poder acceder a la red y compartir estados de ánimo a distancia, expresar aquello que cara a cara no pueden decir o jugar con sus identidades.

La pregunta que indaga por la frecuencia de uso de Internet es altamente significativa, ya que revela el uso diario que es el mayor indicador $(67,29 \%$, frente a quienes lo hacen semanalmente (26,5\%). Esto equivale a un altísimo 93,7\% del total de los encuestados que permanecen conectados vía Internet de manera diaria o semanal. El porcentaje es mínimo de aquellos que no se conectan nunca (2,2 \%).

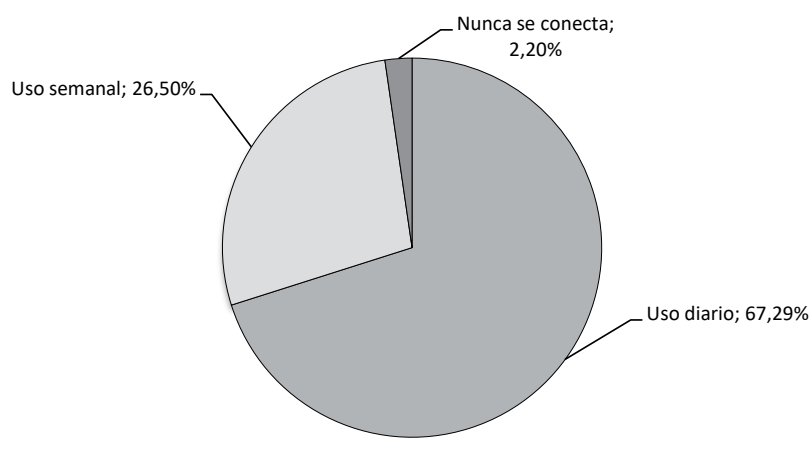

Gráfica 5. Frecuencia uso de internet

Fuente: elaboración propia

En este sentido, es claro que los jóvenes han interiorizado el discurso según el cual el futuro depende, en gran medida, del progreso tecnológico y del control de las nuevas tecnologías. Saben que su porvenir social y profesional les exigirá ser competentes en el uso de estas herramientas. De igual manera, los jóvenes son conscientes de la preocupación de los padres y profesores acerca del uso que ellos hacen de estas tecnologías.

En relación con los intereses desde los cuales los jóvenes acceden a Internet, significativamente el 54,2 \% lo hace por entretenimiento, porcentaje seguido de aquellos que seleccionaron satisfacer expectativas de orden informativo (32,9\%) o educativo $(24,6 \%)$.

Es claro, si nos atenemos a las respuestas de los encuestados, que Internet, más que una herramienta educativa, incentiva el disfrute y el placer para un gran porcentaje de la población joven, con lo que habría que pensar en promover proyectos de análisis / intervención dirigidos a auscultar las formas de consumo digital de la población juvenil y la manera como este consumo en particular incide en la utilización del tiempo libre. 


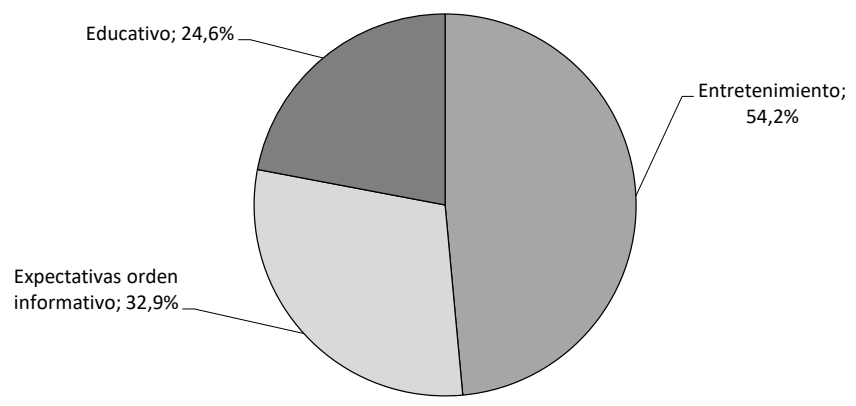

Gráfica 6. Interés de jóvenes que acceden a internet

Fuente: elaboración propia

Al mostrar la preferencia de los jóvenes respecto a las páginas y portales: en primer lugar aparece Facebook (50 \%), y en menor medida la mensajería instantánea (Whatsapp) con 27,3\% y el portal especializado en música y vídeo YouTube con un porcentaje de 34,7\%.

Los jóvenes del departamento del Meta acceden a Internet a través de dispositivos móviles en un $74,1 \%$, y están adscritos a redes sociales e un $69,1 \%$.

Este es un hecho trascendental, que consolida la importancia de las comunidades virtuales en el mundo juvenil, sus necesidades de adscripción a grupos de pares, las formas en que establecen sus relaciones en la actualidad y la aparente consolidación de lo que los investigadores sociales han denominado la emergencia de una nueva estructura social: la sociedad red (Castells, 2006).

\subsection{Consumo audiovisual}

En cuanto a programas de televisión preferidos, los jóvenes manifiestan en un 36 \% (1 083) de favoritismo por melodramas televisivos (novelas), seguido por programas de comedia (764, 25,4 \%) y acción (687, 22,8 \%). La ciencia ficción ocupa la atención de 450 jóvenes $14,9 \%$ y los realities de 444 (14,7\%). Los programas informativos y noticiosos no atraen la atención de los jóvenes habitantes del departamento del Meta por ser considerados muy rígidos y serios. En su lugar, parte de las dificultades que tienen muchos de los jóvenes tratan de asumirlas observando programas menos "tediosos", que muchas veces puedan sacarlos de las dificultades en las que se encuentran y relajarlos del mundo en que viven. Es relevante destacar que el horario preferido para ver televisión en los jóvenes del departamento del Meta es la noche, con un $60.5 \%$, comparado con un porcentaje de 31,6 $\%$ que prefiere hacerlo en el horario de la tarde y $16,5 \%$ que ve televisión en horas de la mañana, horarios relacionados con sus ritmos biológicos, académicos y vitales.

La muestra de jóvenes representada incluyó que en un 63,82 \% tiene conexión de cable, seguido de $26,15 \%$ de televisión abierta y en menor proporción (8,6 \%) la televisión satelital. 


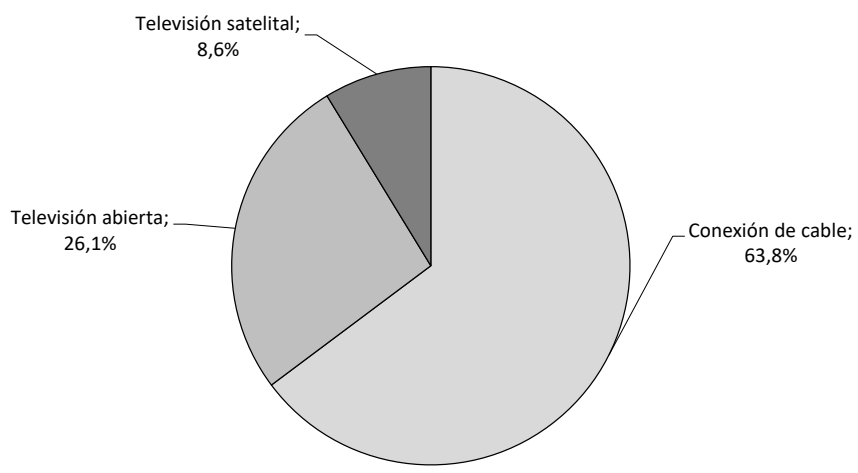

Gráfica 7. Consumo audiovisual

Fuente: elaboración propia

\section{Conclusiones}

En primera medida, es muy destacable el hecho de una falta de concreción frente al concepto de cultura y su importancia para los seres humanos, ya que se pueden claramente evidenciar diferencias radicales en sus apreciaciones, que van desde la idea esencialista y totalizante que la define como el espacio "donde nosotros nos desarrollamos mentalmente, donde tenemos que convivir con personas, donde expresamos nuestra forma de vivir", o aquella según la cual "es todo lo que rodea al ser humano desde que nace hasta que muere... todo lo que tiene que ver con la formación y con nuestro encauzamiento en la sociedad", hasta las más elaboradas que la conciben con "elementos muy complejos frente a la concepción de elementos que nos generan una identidad como seres humanos, frente a las concepciones de ya sea dentro de los más individual: los elementos de carácter personal, como la concepción de la personalidad, la subjetividad o dentro de los aspectos más colectivos frente a concepciones de esas identidades. Precisamente que tiene que ver con los elementos de una territorialidad o en el caso ya de un de un país con la concepción de una nacionalidad", o, en fin, aquellas nociones simplistas según las cuales la cultura constituye un "espacio de esparcimiento para formar capacidades y focalizar energías".

Es muy importante, sin embargo, reconocer que los jóvenes habitantes del departamento del Meta tienen gran reconocimiento a la cultura en cualquiera de sus manifestaciones. Los ámbitos culturales, por tanto, generan en ellos profunda significación, lo que debe necesariamente ser tenido en cuenta por las agencias culturales. Satisfacer sus expectativas consolidaría, en buena medida, su inclusión como ciudadanos y sujetos de derecho.

Tal como se puede deducir de las entrevistas realizadas, así como de las encuestas, la familia incide de manera significativa en la importancia que se otorgue al tema cultural en los jóvenes. 
La oferta cultural para el mundo juvenil debe ser repensada seriamente, pues en voces de los propios jóvenes no existe una suficiencia en términos de actividades que satisfagan sus expectativas, no hay políticas orientadas hacia sus gustos y preferencias en la materia, las agencias no cumplen en muchas oportunidades con sus responsabilidades, se presenta una excesiva orientación cultural de corte patrimonial o eventos de carácter masivo que, para los muchachos, no producen los efectos que se requieren para consolidar la cultura como un elemento primordial para el desarrollo de los sujetos. Incluso, a través de opiniones que afirman la importancia de la cultura para el desarrollo social, la solución de los problemas que afectan a los jóvenes y la búsqueda de la paz: "a través de la cultura se puede cambiar esa manera de pensar (...) el municipio sí necesita más arte, más instituciones culturales deportivas que cambien esa manera de pensar del joven".

Áreas artísticas como el teatro o las artes visuales, en la manifestación de los jóvenes no generan entusiasmo, lo que produce índices muy bajos de asistencia a eventos de esta naturaleza. Estudios más detallados podrían concluir las razones, entre las que se podrían encontrar escasa oferta en tales ámbitos, inexistencia de espacios de capacitación consolidados para la divulgación de sus formatos y la creación y consolidación de públicos, inexistencia de espacios dedicados a su divulgación (museos, salas de teatro), etc. Se sugiere a las agencias culturales hacer especial énfasis en estas dos importantes manifestaciones artísticas.

El cine, como herramienta pedagógica y mediación cultural, ha demostrado suficientemente ser un importante escenario de divulgación de la cultura local, regional y mundial. Acceder a sus lógicas y sus gramáticas se ha convertido en un elemento definitivo para las sociedades contemporáneas. Queda la inquietud respecto de los géneros que observan los jóvenes en el departamento del Meta, pues al parecer el cine independiente es de poco reconocimiento en la ciudad.

Las herramientas tecnológicas (TIC) están resignificando las estructuras sociales a escala planetaria. La situación en el departamento del Meta no podría ser una excepción: sus jóvenes demuestran muy claramente la importancia que Internet tiene en sus vidas, cómo acceden cotidianamente, cuáles son sus preferencias en términos de satisfacción de necesidades y las comunidades virtuales a las cuales se encuentran inscritos. La evidencia de los nativos digitales (Prensky, 2001) significa un reto muy interesante para la generación de políticas culturales de los jóvenes que satisfagan sus expectativas y, por supuesto, que generen elementos de reflexión sobre el uso adecuado del tiempo libre, así como sus efectos formativos.

Una revelación un tanto pesimista la constituye el muy bajo índice de importancia e interés que los jóvenes le asignan a la lectura. Ello se suma, lamentablemente, a las bajas frecuencias con que lo hacen, al carácter instrumental con que se dedican a leer, así como a los ya demostrados bajos indicativos de interpretación de la lectura en pruebas de los órdenes nacional e internacional, otro gran reto tanto para las agencias dedicadas a la promoción de la cultura como para las instituciones educativas, las organizaciones juveniles, el Estado seccional, etc. 
El comentario proviene de alguno de los sujetos entrevistados, y es acaso concluyente y contundente:

En la infraestructura falta mucho, pero también en la gestión cultural, en la forma de cómo la gente se apropia de esos espacios y dentro de los pocos espacios infraestructuralmente adecuados muchas veces son desaprovechados..., hay también desde otro punto no solo la cuestión de cómo se construye la cultura desde la institucionalidad, la formalidad, sino cuál es papel de la comunidad frente a esa gestión cultural y en el departamento es muy poca la atención que se está dando ahí.

La música es un área cultural fundamental para la población objeto de análisis: a través de las ondas radiales, en sus hogares, pero también en bares y tabernas, los jóvenes mantienen una especial preferencia por la música en todos sus géneros. El joven no tiene claras preferencias musicales, sino que, eventualmente por al carácter sincrético de sus formatos identitarios, gusta de muchos géneros en forma simultánea. Un buen indicativo para ofrecer actividades dedicadas a promover la producción, distribución y programación musical en diferentes escenarios.

Llama la atención el hecho de que un porcentaje significativo de la población juvenil no asiste a eventos de carácter autóctono tradicional. La razones podrían estar orientadas hacia cierta incomodidad que sienten hacia las formas tradicionales de la cultura (considerada atrasada o bárbara), o como rechazo a cierta desatención de sus gustos y expectativas por parte de las agencia culturales.

En cuanto a la relación existente entre cultura y desarrollo, los jóvenes encuentran en esta intersección una importante fuente para solucionar algunas de las problemáticas más relevantes de la sociedad actual.

[...] Una sociedad es necesario que se desarrolle... es, digámoslo de cierta manera, que para una sociedad un primordial sentido es tener siempre una calidad de vida óptima... nadie puede ser distante de ella y creo que eso es lo que nos han impartido y creo que es lo que hace que el individuo se esfuerce y es por mantener sus mínimos, unas mínimas condiciones de vida... y muchas veces esa cultura, esa reformación va acompañada para dar un buen desarrollo de una sociedad que llegue a ser activa... que llegue a permitirle a todos sus ciudadanos, a todos sus miembros ser partícipes de ella y que ellos se puedan sentir conformes.

La cultura no se escenifica exclusivamente en los espacios y los escenarios considerados convencionales (museos, salas de arte, auditorios), sino en los espacios en los que los jóvenes comparten sus significados con sus pares y con los otros integrantes de la sociedad. En este sentido, los centros comerciales, los bares, los "parches", los sitios de encuentro tienen un enorme significado para sus actividades performativas. De ahí que sea necesario generar procesos de comprensión relacionados con dichos lugares, con su significación y con la importancia que estos actores sociales le otorgan. 


\section{Referencias bibliográficas}

Avelló F., J. y A. Muñoz, G. (2002) "La comunicación desamparada. Una revisión de paradojas en la cultura juvenil" en F. Rodríguez. Comunicación y cultura juvenil. Barcelona, Ariel.

Barbero, J. M. (1998). "Jóvenes desorden cultural y palimpsestos de identidad. En "Viviendo a toda". Jóvenes, territorios culturales y nuevas sensibilidades. Bogotá: Siglo del Hombre Editores.

Barbero, J. M. (2002). "Jóvenes: comunicación e identidad". En Revista Pensar Iberoamérica. N.º, febrero.

Castells, M., et al. (2004). The network society in Catalonia: An empirical análisis. [En línea]. Barcelona: Universitat Oberta de Catalunya. Disponible en: http://www.uoc.edu/in3/pic/eng/pdf/pic $1 . p d f$

Castells, M. (2006). La sociedad red: una visión global. Madrid: Alianza Editorial.

FEIXA, C. (2000), "Generación @. La juventud en la era digital", en Nómadas núm. 13, Bogotá, pp. 76-91. . (1995). "Tribus urbanas y Chavos banda: las culturas juveniles en Cataluña y México". Nueva Antropología, Revista de Ciencias Sociales. N. ${ }^{\circ}$ 47, pp. 71-93.

. (1993). "La juventud como metáfora". Generalitat de Catalunya, Barcelona.

García Canclini, N. (1990). Culturas híbridas. Estrategias para entrar y salir de la modernidad. México: Grijalbo.

García Canclini, N. (1999). La globalización imaginada. México: Paidós. . (1999). La globalización imaginada. Barcelona: Paidós.

Habermas, J. (1982). Conocimiento e interés. Madrid: Taurus.

Hurtado Herrera, D.R. (2007). "La configuración de significaciones imaginarias de deseo en jóvenes urbanos de la ciudad de Popayán", tesis doctoral.

Hobsbawm, E. (1995). Historia del siglo XX. Madrid: Crítica.

Hobsbawm, E (2013). Un tiempo de rupturas: sociedad y cultura en el siglo XX. Madrid: Crítica.

Maffessoli, M. (2004). "Juventud: el tiempo de las tribus y el sentido nómada de la existencia", en Revista Joven-es N. ${ }^{\circ} 20$, México D. F., pp. 28-41.

Marín, M., E Muñoz, G. G. (2002). Secretos de mutantes. Música y creación en las culturas juveniles. Bogotá: Siglo del Hombre Editores.

Muñoz González, G. (2007). "La comunicación en los mundos de vida juveniles", Revista Latinoamericana de Ciencias Sociales, Niñez y Juventud, 5 (1), pp. 35-56.

Prensky, M. (2001). "Nativos Digitales, Inmigrantes Digitales", From On the Horizon (NCB University Press, Vol. 9 N. ${ }^{\circ}$, october.

Reguillo, R. (2000). Emergencias de culturas juveniles. Estrategias del desencanto. Buenos Aires: Grupo Editorial Norma.

Reguillo, R. (2003). "Las culturas juveniles: un campo de estudio; breve agenda para la discusión", en Revista Brasileira de Educaçao N. ${ }^{\circ} 23$, pp. 103-118.

Sandoval Casilimas, C. A., (1996). "Enfoques y modalidades de investigación cualitativa", Bogotá, ICFES.

Sassen, S. (2007). Una sociología de la globalización, Buenos Aires, Katz Editores.

Sunkel, G. (2006). El consumo cultural en América Latina. Bogotá: Convenio Andrés Bello. 